\title{
La racionalidad ecológica de los costos históricos y el conservadurismo*
}

\author{
[Artículos]
}

Eduard Braun**

Recibido: 30 de noviembre de 2020

Aprobado: 15 de junio 2021

Citar como:

Braun, E. (2021). La Racionalidad Ecológica de los Costos Históricos y el Conservadurismo. Revista Activos, 19(1). https://doi.org/10.15332/25005278.6679

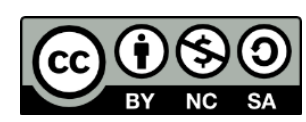

\section{Resumen}

Los principios que caracterizan el enfoque tradicional de ingresos y gastos en la contabilidad no pueden remontarse a un evento histórico particular; son racionales ecológicamente. Su funcionalidad es la consecuencia de la evolución cultural y no de un diseño humano específico. Esta es la razón por la que los esfuerzos por defender el

\footnotetext{
* El texto fue publicado originalmente en inglés en Accounting, Economics, and Law: A Convivium, vol. 9, no. 1, 2019. Para esta versión en español, se contó con la colaboración y aprobación del autor, el editor de la mencionada revista (Yuri Biondi - University Paris Dauphine PSL) y la editorial De Gruyter. La traducción fue realizada por Carlos Orlando Rico Bonilla, profesor de la Facultad de Contaduría Pública de la Universidad Santo Tomás. Correo electrónico: carlosricob@usantotomas.edu.co

El autor agradece a los profesores Mathias Erlei, Thomas Schildbach y Andreas Scholze por sus útiles comentarios sobre los borradores anteriores de este documento. Además, se benefició de las discusiones con varios participantes de la Annual Conference of the British Accounting and Finance Association y las observaciones formuladas por los asistentes del Austrian Economics Research Seminar at ESCP Europe, París.

${ }^{* *}$ Institute of Management and Economics, Clausthal University of Technology, Alemania. Correo electrónico: eduard.braun@tu-clausthal.de; ORCID: http://orcid.org/0000-0002-1752-4287
}

\section{Revista Activos}

ISSN: 0124-5805 | e-ISSN: 2500-5278 | DOI: https://doi.org/10.15332/25005278

Vol. 19 N.० 1 | enero-junio de 2021 
enfoque de activos y pasivos, avalado por los emisores de estándares, han encontrado dificultades sustanciales. Solo este último enfoque se basa claramente en un modelo económico puntual: la economía neoclásica. En contraposición, se argumenta que una base sólida para explicar la racionalidad de los principios de contabilidad que evolucionaron culturalmente se puede encontrar en la economía del comportamiento. Estos principios están en línea con las conductas humanas que se han evidenciado en numerosos experimentos de campo y laboratorio. Especialmente con respecto a la teoría prospectiva, se identifica un paralelo cercano.

Además, este análisis se combina con una visión del proceso de mercado en la economía. La contabilidad financiera según el enfoque de activos y pasivos no agrega nueva información al mercado, solo resume a nivel de la empresa la información proporcionada por este. Por el contrario, el enfoque de ingresos y gastos suministra información privada al mercado, al estilo de lo descrito por Hayek (1945). El enfoque de ingresos y gastos resulta, por tanto, compatible con la organización de la economía de mercado.

Palabras clave: contabilidad financiera, teoría prospectiva, conservadurismo, costos históricos, racionalidad ecológica.

Clasificación JEL: M41.

\section{The ecological rationality of historical costs and conservatism}

\section{Abstract}

The principles characterizing the traditional revenue-expense approach to accounting cannot be traced back to a particular historical event; they are ecologically rational. Their functionality is the result of cultural evolution, not of a specific human design. This is why efforts to defend the assets and liability approach, endorsed by standard-setters have 
encountered serious difficulties. Only the latter approach is clearly based on a specific economic model: neoclassical economics.

In contrast, it is argued that a solid basis for explaining the rationale of the culturally evolved accounting principles can be found in behavioral economics. These principles are in line with human behavior as found in numerous laboratory and field experiments. Especially with respect to prospect theory, a close parallel is identified.

Furthermore, this analysis is combined with a view of the market process in the economy. Financial accounting according to the asset-liability approach does not add new information to the market process, it only summarizes at company level the information provided by the market. In contrast, the revenue-expense approach provides private information to the market as described by Hayek (1945). The revenue- expense approach thus results compatible with the organization of the market economy.

Keywords: financial accounting, prospect theory, conservatism, historical costs, ecological rationality

JEL classification: M41.

\section{Introducción}

Desde principios de la década de 1970, el Financial Accounting Standards Board (FASB) y el International Accounting Standards Committee (IASC), que luego se convirtió en la International Accounting Standards Board (IASB), han intentado desarrollar y difundir estándares de contabilidad financiera que contrastan fuertemente con los principios de contabilidad que han evolucionado históricamente (Littleton, 1933; Ijiri, 2005; Biondi, 2011a). Por muchas y diversas razones, el desplazamiento de los antiguos principios ha sido severamente criticado.

En una serie de artículos reveladores, Dickhaut (2009), Dickhaut et al. (2009; 2010) y Waymire (2014) proporcionan nuevos argumentos contra 
la abolición de estos principios en favor de los definidos por los dos principales emisores de estándares contables. Muestran que algunos de los principios contables más importantes, conectados con el enfoque tradicional de ingresos y gastos, como el costo histórico y el conservadurismo, son compatibles con los hallazgos de la neurociencia. Los autores discuten que estos principios culturalmente evolucionados deben tener un significado más profundo que puede redescubrirse en la lógica del cerebro humano. El presente documento fundamenta esta afirmación.

Vinculando investigaciones novedosas como Waymire y Basu (2007, 2011), Basu (2009) y Sunder (2005), se trata de clarificar la racionalidad que hay detrás de dicha evolución. De hecho, hay más que tradición tras estos conceptos, que no son de modo alguno arbitrarios, sino que hay similitudes sistemáticas entre ellos y otros aspectos del pensamiento y la conducta humana. Especialmente, la economía del comportamiento suministra un campo de juego fértil, complementario a la neurociencia, para quienes buscan casos en los que la lógica de estos principios emerge en situaciones relevantes.

El costo histórico y el conservadurismo son características comunes del comportamiento humano. Se argumenta que este paralelo no es una coincidencia. Aunque los rasgos de conducta que corresponden a estos principios a veces se describen como incoherentes o anomalías, parecen conferir una ventaja evolutiva para quienes se adhieren a ellos en un entorno de incertidumbre.

En el contexto de un proceso de ensayo y error, los principios "irracionales" parecen tener mucho sentido. Los costos históricos, por 
ejemplo, aunque se refieren a costos hundidos ${ }^{1}$, ayudan a generar información sobre la magnitud de las consecuencias tanto positivas como negativas de decisiones pasadas; el conservadurismo puede no garantizar la maximización del beneficio, pero aumenta la probabilidad de sobrevivir a tiempos difíciles. Por tanto, los principios contables tradicionales pueden seguir siendo pertinentes incluso si nadie los ha diseñado lógicamente. Su racionalidad es, en la terminología de Vernon Smith (2003), ecológica; en otras palabras, dichos principios son el efecto inconsciente de un proceso evolutivo donde la conducta se adapta gradualmente al entorno.

$\mathrm{El}$ argumento de este documento consta de dos partes. En la primera, se sostiene que la contabilidad financiera, si se lleva a cabo de acuerdo con el costo histórico y el conservadurismo, se ajusta a lo establecido por la economía del comportamiento. La relevancia de esta rama de la economía y la piscología para la investigación contable se ha señalado anteriormente (Koonce y Mercer, 2005; Fennema y Koonce, 2010); sin embargo, con la excepción de Hirshleifer y Teoh (2009), los preceptos de esta disciplina solo se han aplicado superficialmente al análisis y diseño de principios contables.

Por tanto, en el apartado 3, se establece una relación entre los principios tradicionales y la economía del comportamiento. Los emisores de estándares restan importancia al conservadurismo y al costo histórico porque no pueden conciliarse con los supuestos normativos de la economía neoclásica. Incluso, algunos miembros destacados de las escuelas de la economía austriaca y la institucional, que generalmente se oponen al neoclasicismo moderno, han contribuido con este desarrollo (3.1).

\footnotetext{
${ }^{1}$ Se refieren a las erogaciones retrospectivas, que ya se han incurrido y no pueden ser recuperadas a futuro, por lo que también se les denomina costos irrecuperables (N. del T.).
} 
No obstante, los principios contables tradicionales se ajustan a los resultados de la economía del comportamiento, es decir, están en consonancia con las conductas humanas evidenciadas en numerosos experimentos de campo y laboratorio. Por tanto, este documento se concentra en la teoría prospectiva ${ }^{2}$ (Kahneman y Tversky, 1979), una propuesta fundamentada experimentalmente que ofrece un trasfondo contra el cual estos principios pueden interpretarse de una nueva manera. En esta línea, el enfoque de ingresos y gastos puede conciliarse con estas ideas, mientras que la aproximación de activos y pasivos que respaldan los emisores de estándares no (3.2). Así mismo, el argumento de los costos hundidos, que a menudo se presenta en contra de la forma tradicional de contabilidad, también se ve cuestionado a la luz de la teoría prospectiva y las investigaciones asociadas. La gente no se olvida de estos costos como asume la teoría neoclásica de la decisión; por el contrario, los tiene muy en cuenta (Thaler, 1980; 1999). Lo mismo se hace en la contabilidad clásica: los costes históricos no se olvidan, sino que se registran en el balance general (3.3).

Además, la función de valoración asimétrica ${ }^{3}$ desarrollada en la teoría prospectiva es consistente con el principio contable del conservadurismo (Dickhaut et al., 2010) (3.4). Aparentemente, los principios contables tradicionales alinean el comportamiento de las empresas con el de las personas. Siempre que las empresas practiquen la contabilidad de acuerdo con estos lineamientos, las cifras del resultado se determinan de un modo

\footnotetext{
${ }^{2}$ Es un modelo que permite describir cómo las personas toman decisiones en escenarios en los que enfrentan diferentes prospectos o alternativas que implican riesgos e incertidumbre (N. del T.).

${ }^{3}$ Es un esquema que representa el marco de elección de las personas, como un escenario en el que estas experimentan una utilidad subjetiva, de satisfacción o desagrado, con relación a la percepción de ganancias y, con mayor énfasis su apreciación de las pérdidas, de ahí su carácter asimétrico (N. del T.).
} 
que se ajusta a la conducta humana, como se revela en numerosos experimentos.

La segunda parte del argumento principal, que se expone en el apartado 4, consiste en la explicación de por qué estos principios, si bien se ajustan a modos de comportamiento que violan la racionalidad postulada por la economía neoclásica, no obstante, han triunfado en la evolución de las instituciones. El hecho de que los principios contables tradicionales hayan cambiado a lo largo del tiempo como lo han hecho, es una señal de su racionalidad ecológica (Smith, 2003; 2005; 2008). Estos se desarrollaron como consecuencia de la acción humana pero no de un diseño humano intencionado (Ferguson, 1767; Hayek, 1967a; Waymire y Basu, 2008; Sunder, 2005); la razón fundamental de su existencia y su configuración no tiene por qué ser obvia (4.1).

Los principios contables tradicionales son más bien el efecto no planificado de un largo proceso de ensayo y error en el que se han puesto a prueba diferentes reglas. Más notablemente, después de las crisis económicas y financieras, con regularidad ha habido una importante tendencia hacia la contabilidad de costos históricos y el conservadurismo (4.2). Al parecer, estos principios descansan en reglas de conducta que aseguraron la supervivencia de nuestros antepasados y, por tanto, también aumentan la probabilidad de sobrevivir en el mercado (Waymire y Basu, 2011; Basu, 2015).

En este sentido, mientras que el conservadurismo y el costo histórico no están en consonancia con la economía neoclásica, son aún más razonables desde el punto de vista del proceso de mercado. La función de coordinación de este no requiere que los participantes tengan datos completos o perfectos, sino, únicamente, información privada en los términos de Hayek (1945). La contabilidad financiera según el enfoque tradicional de ingresos y gastos proporciona esta información, mientras 
que en el enfoque de activos y pasivos no se agregan nuevos datos al mercado; solo se resume, a nivel de la empresa, la información suministrada por este (4.3).

El IASB y el FASB inhiben los procesos que son necesarios para que evolucionen los principios contables racionales ecológicamente. Ellos tienden a diseñar intencionalmente sus estándares y, además, apuntan a la uniformidad en todo el mundo. De esta manera, la competencia entre diferentes principios queda más o menos excluida y la capacidad de aprehender de la experiencia se ve limitada (Dye y Sunder, 2001) (4.4).

Al reunir dos líneas de literatura separadas - la economía del comportamiento y la racionalidad ecológica de las instituciones- y aplicarlas al tema de la contabilidad financiera, el documento contribuye a comprender la lógica de los principios contables tradicionales. En el siguiente apartado, el epígrafe 2, se hace una breve presentación de las dos visiones de la contabilidad que son relevantes para la discusión: la visión tradicional y la respaldada por los emisores de estándares.

\section{Dos aproximaciones a la función de la contabilidad}

La contabilidad financiera, como sostuvieron Werner Sombart, Max Weber, Ludwig von Mises y Joseph Schumpeter, es una institución central, si no definitoria, de la economía de mercado y el capitalismo (Waymire y Basu, 2008, p. 3). En su famoso argumento, Mises (1920) señaló que el socialismo está condenado al fracaso porque no puede basarse en lo que él llamó "la contabilidad del capital"4. Las raíces de la contabilidad, como se la conoce hoy, retroceden al menos a la Europa medieval donde, en 1494, Luca Pacioli publicó la primera descripción impresa de la teneduría de

\footnotetext{
${ }^{4}$ En cierto sentido, podría decirse que la contabilidad no solo se adapta a su entorno socioeconómico, sino que, a la inversa, también tiene el potencial de influirlo y modificarlo. Este documento no sigue esta idea, sino que se centra en cómo y por qué los principios contables evolucionaron (N. del A.).
} 
libros por partida doble, tal y como se practicaba en las prósperas ciudades italianas de su tiempo (Hatfield, 1924, pp. 6 y ss.; Zan, 1994, p. 263; Sangster, 2010).

En los últimos 150 años, la forma en que esta antigua y esencial institución se ha abordado por los académicos y los políticos ha cambiado considerablemente. Mientras que en épocas anteriores el papel de la investigación contable y la legislación comercial era describir y establecer cuáles eran las prácticas contables más pertinentes y sólidas, sin interferir activamente, la tendencia actual es hacia la aplicación de principios contables que van en contra de las tradiciones. En el siglo XIX, esto se manifestó notablemente en Alemania, donde, en dos pasos entre 1861 y 1870, la ley comercial alemana abolió la regla de costo histórico y, en su lugar, impuso lo que hoy se llamaría la contabilidad del valor razonable en las corporaciones (Hoffmann y Detzen, 2013).

Luego de demostrarse que esto incrementó severamente la especulación y los fraudes que precedieron a la crisis de 1873, se volvió a cambiar la ley y las reglas tradicionales volvieron a cobrar vigencia (Braun, 2014). Durante los últimos cuarenta años, la orientación hacia el establecimiento de estándares contables obligatorios se ha acelerado (Biondi, 2011a, p. 2). Especialmente desde la fundación del FASB y el IASC, los principios tradicionales han perdido importancia y, poco a poco, están siendo reemplazados por reglas diseñadas.

Aunque hay muchos cambios detallados que merecen un tratamiento más detenido, este documento se centra en el panorama general, es decir, en la diferencia fundamental entre los principios contables tradicionales y los diseñados por los dos grandes emisores de estándares. Esta divergencia se manifiesta en la manera que se interpreta la función misma de la contabilidad financiera. Básicamente, existen dos enfoques alternativos (Dichev, 2008, p. 454). 
Los principios contables tradicionales evolucionaron de una manera que se hicieron adecuados para determinar los beneficios de una entidad contable (Littleton, 1953, pp. 18-35). Inicialmente, Eugen Schmalenbach ([1919] 1959; véase también Dichev, 2008, p. 455) trabajó en analizar esta relación. Él argumentó que la única función central de la contabilidad financiera, si se realiza de acuerdo con el principio de costo histórico, es determinar el éxito de la compañía comparando los gastos incurridos y los ingresos realizados, y concluyó que, el estado de resultados debe verse como el documento decisivo (Schmalenbach, [1919] 1959, p. 32). En cambio, el balance general donde se expresan los activos y pasivos solo tiene una función subordinada. Se ha vuelto necesario porque la mayoría de las empresas, especialmente desde la revolución industrial, son negocios en marcha y no tienen una fecha de liquidación previsible. Para estas empresas que pagan rendimientos a sus accionistas de forma regular, y no solo en el momento de la liquidación, es necesario mantener fuera del estado de resultados todas las transacciones que aún no se han completado, es decir, para las que no se pueden definir unos beneficios determinados. Esto incluye de manera más notable los gastos corrientes que se supone que darán lugar a ingresos en el largo plazo y, así mismo, a los ingresos corrientes que implican gastos en el futuro.

Así, el balance general, según la interpretación de Schmalenbach (1959, p. 55), sirve como un almacén de partidas no vencidas para el estado de resultados. Es, en sus propias palabras, una "valiosa ayuda para la memoria y, por así decirlo, describe el almacenamiento de energía [Kräftespeicher] de la empresa" (Schmalenbach, 1933 p. 121). Contiene, para dar un pequeño ejemplo, los gastos históricos que se han realizado por una máquina. Estos solo entran al estado de resultados a lo largo de los años, como depreciaciones, mientras que este bien se desgasta. 
Schmalenbach llamó a esta visión tradicional de la contabilidad el enfoque “dinámico". En este documento, se denominará enfoque de ingresos y gastos o de resultado. Gino Zappa y su escuela desarrollaron ideas similares en Italia al mismo tiempo (Canziani, 2013, pp. 75-79). Este enfoque alcanzó su epítome en los Estados Unidos con la publicación de Paton y Littleton (1940), que también se centró en el estado de resultados y relegó el balance general a un "estado periférico" (Dichev, 2008, p. 455; ver también Mattessich, 2013, p. 20). Estos académicos influyeron fuertemente y dieron forma al pensamiento y la práctica contable hasta el día de hoy, tanto en los Estados Unidos como en el resto del mundo (Markarian, 2013, pp. 321-324; 2014, p. 47).

El IASB y el FASB, por el contrario, promueven lo que Schmalenbach llamó el enfoque "estático", que hoy en día se denomina más bien el enfoque del balance (Perry y Nölke, 2006, p. 563) o de activos y pasivos. El propósito principal de la contabilidad, según este punto de vista, es brindar información relevante para el mercado de capitales, especialmente a inversores actuales y potenciales (Barth, 2006, p. 272; Hitz, 2007, p. 327). Por lo tanto, desde esta óptica de la contabilidad que los emisores de estándares están propagando y aplicando, el balance general es el estado financiero crucial. Este contiene -o esto se supone- información útil sobre la situación financiera de la firma. Idealmente, debería proporcionar el "valor razonable" de todos los activos y pasivos de esta.

La contabilidad del valor razonable, por lo tanto, encaja en el enfoque del balance (Hitz, 2007, p. 328). Se supone que proporciona información sobre el valor presente de los flujos de efectivo futuros que se espera que generen las respectivas partidas (Biondi, 2011a). El IFRS 13.9 acentúa la base de mercado del concepto al especificar que el valor razonable es el "precio que se recibiría por vender un activo o el que se pagaría por transferir un pasivo en una transacción ordenada entre participantes del 
mercado en la fecha de medición". En síntesis, el "valor razonable" básicamente significa el valor presente de los flujos de efectivo que van a producir las partidas del balance general y cuyo precio en un mercado eficiente es el mejor proxy (Barlev y Haddad, 2003, p. 397).

Si los precios de mercado no exhiben una calidad suficiente - por ejemplo, porque en los mercados subyacentes se negocia poco o no están disponibles en absoluto-, los emisores de estándares requieren el uso de valores (modificados) de artículos comparables, donde la comparabilidad se refiere a un perfil del flujo de efectivo similar. Cuando el ajuste al mercado es imposible, como técnica de último recurso, el valor razonable debe definirse utilizando estimaciones y cálculos internos (marking-tomodel) (Hitz, 2007, p. 326 y ss.). Para resumir, el balance general no se interpreta como un depósito para el estado de resultados, sino como un dispositivo que contiene pronósticos de flujos de efectivo futuros.

Como para los emisores de estándares, el objetivo principal de la contabilidad es informar al mercado de capitales, se oponen a la antigua visión del enfoque de ingresos y gastos. Un balance general basado en costos históricos no proporciona una imagen razonable de la "real situación financiera" de una firma (Barlev y Haddad, 2003, pp. 384-387). Además, de acuerdo con el enfoque del balance, los ingresos solo juegan un papel subordinado (Dichev, 2008, p. 454). El resultado integral es la diferencia entre el valor presente de los activos netos de la compañía según lo determinado por la contabilidad a valores razonables-al comienzo del periodo y su valor al final del este (Barth, 2006, p. 272; Rayman, 2007, p. 217). Por tanto, el balance general ya no es el "sirviente" del estado de resultados, sino que, por el contrario, este se convierte únicamente en su correlato. 


\section{La teoría prospectiva y su relación con los principios de contabilidad}

\subsection{Las raíces neoclásicas de los estándares actuales}

La economía y la contabilidad se han enriquecido mutuamente durante mucho tiempo. Originalmente, fue la economía la que asumió muchos conceptos importantes, como 'capital', 'costos' e 'ingresos', de las prácticas contables (Klamer y McCloskey, 1992; Chiapello, 2008). Sin embargo, aproximadamente desde la década de 1960, la dirección de la influencia se ha invertido (Dillard, 2008). En cuanto a su método, los estudios contables de la corriente principal moderna están orientados por el programa de investigación positivista de la economía (y más tarde de las finanzas) que fue propuesto por Paul Samuelson y John Hicks (Kohn, 2004) y que fue resumido y motivado por Milton Friedman (1953) en su ensayo metodológico (Watts y Zimmerman, 1986; Basu, 2015, pp. 244 y ss.). Con el surgimiento de este nuevo método, también conceptos cruciales como la hipótesis del mercado eficiente y el equilibrio general walrasiano ingresaron a la investigación contable desde la economía, principalmente a través de su rama financiera (Williams y Findlay, 1980, pp. 133-135).

En este sentido, se ha observado muchas veces que el enfoque contable del balance, y especialmente la noción del valor razonable, se basan en la economía neoclásica (Hitz, 2007, p. 327, 332). Principalmente, la discusión de John Hicks (1946) sobre los ingresos netos5 es utilizada como punto de referencia por los emisores de estándares (Bromwich et al., 2010, p. 350). Apuntan explícitamente al ingreso $n .^{\circ} 1$ expuesto por este autor

\footnotetext{
${ }^{5}$ En inglés se utiliza el término revenue, para lo que se denominaría en español como los ingresos brutos, y el de income para los ingresos netos o rentas, que son otra manera de llamar a los resultados (earnings), que pueden ser ganancias o pérdidas. El concepto de 'ingreso' de Hicks se refiere como tal a los ingresos netos (N. del T).
} 
(Barth, 2006, p. 280), que a menudo también se le denomina "ingreso económico" (Solomons, 1961, pp. 375ss). Este concepto es: "la cantidad máxima que se puede gastar durante un periodo si hay una expectativa de mantener intacto el valor del capital de las entradas calculadas (en términos monetarios)" (Hicks, 1946, p.173).

En esta definición se prioriza claramente el balance general y la valoración de activos y pasivos. Según Bromwich et al. (2010, p. 351; ver también Solomons, 1961, p. 376), se podría describir como la diferencia entre el valor de la firma (valor actual neto de los flujos de efectivo futuros) al final de un periodo y el valor de esta al comienzo del periodo más los dividendos distribuidos entre esas fechas. Por tanto, este ingreso es solo un derivado de la determinación del valor presente de los activos y pasivos.

Lo que se acaba de indicar no implica que los economistas neoclásicos respalden, necesaria o incluso habitualmente en la práctica, el uso de sus conceptos asociados al equilibrio, como sucede en este caso. Brief (1982) y Jameson (2005) muestran que incluso el propio Hicks estaba en realidad a favor de la orientación de ingresos y gastos en lugar del enfoque del balance. El punto es que tanto el FASB como el IASB consideran a John Hicks como una "autoridad fundacional" (Jameson, 2005, p. 331) e, ignorando sus advertencias, se centran en su concepto de ingresos.

Debe quedar claro que los conceptos y las teorías neoclásicas no se basan ni se supone que se sustenten en postulados realistas (Friedman, 1953). Si se promueve el concepto de 'ingresos' descrito como el "correcto", tal cual lo hacen los emisores de estándares, implícitamente se asume competencia perfecta, información completa y actores racionales, por nombrar los supuestos más relevantes. En otras palabras, se presume que existen mercados para todos los activos y pasivos representativos y que estos son eficientes y están realmente en equilibrio (Beaver y Demski, 1979, pp. 3943; Hitz, 2007, p. 332). De lo contrario, el valor presente de los activos y 
pasivos de la empresa no podría determinarse, ni siquiera definirse de manera significativa, lo que es admitido incluso por los adherentes al programa de valor razonable (Barlev y Haddad, 2003, pp. 405 y ss.). Por lo tanto, al adoptar el marco neoclásico, los emisores de estándares también aceptan la orientación de este en el análisis económico.

Es importante señalar, en este punto, que la demanda por el enfoque del balance y el valor razonable es compartida incluso por las escuelas de pensamiento que, por lo demás, critican decididamente el enfoque del equilibrio neoclásico. Esto podría explicar por qué ha habido pocas críticas profundas a estas nuevas tendencias por parte de la economía académica: incluso, los oponentes de la teoría neoclásica son bastante neoclásicos en lo que respecta a la contabilidad.

En este sentido, es de especial interés indicar que la Escuela Austriaca de Economía, de la que se puede inferir en parte el concepto de 'racionalidad ecológica', utilizado en este trabajo, rechazó los principios tradicionales de valoración. No solo Fetter (1937, p. 9) y Hayek (1935, pp. 275 y ss.), especialmente Ludwig von Mises, quien enfatizó con vehemencia en la importancia del proceso de mercado frente a la restricción neoclásica del equilibrio (Kirzner, 1997, pp. 61 y ss.), mantenía una visión más bien neoclásica de la contabilidad. A diferencia de Waymire y Basu (2010, p. 135), Mises (1966, p. 213) rechazó las viejas costumbres comerciales y las disposiciones tradicionales del derecho comercial porque "han provocado una desviación de los principios sólidos de la contabilidad”. En cambio, abogó por un concepto de ingresos contables que se asemeja bastante al Hicks:

En los balances y en los estados de pérdidas y ganancias, el resultado de las acciones pasadas se hace visible como la diferencia entre el dinero equivalente de los fondos poseídos (activos menos pasivos) al principio y al final del período informado, y como la divergencia entre el equivalente 
monetario de los costos incurridos y los rendimientos brutos obtenidos. En dichos estados, es necesario considerar el equivalente monetario estimado de todos los activos y pasivos distintos del efectivo. Estos rubros deben tasarse en función de los precios a los que probablemente puedan venderse en el futuro o, como es especialmente el caso de los equipos para procesos productivos, en referencia a los precios esperados en la venta de mercancías fabricadas con su ayuda, (Mises, 1966, p. 212, énfasis agregado)

En este pasaje, obviamente se destacan tanto el enfoque del balance como el concepto de 'valor razonable'. No está claro qué teóricos de la contabilidad influyeron en Mises porque, al escribir su tratado general de economía, no citó a ningún autor en apoyo de sus puntos de vista. Sin embargo, su perspectiva es particularmente importante debido a su influencia sobre Raymond Chambers. Como escribe Gaffikin (1989, p. 90), Mises fue "una de las principales fuentes de inspiración de Chambers". En ocasiones, se hace referencia a este académico como el padre del valor razonable, aunque ciertamente esto es una exageración (Gaffikin, 2012; Barlev y Haddad, 2003, p. 390). En cualquier caso, fue un influyente teórico de la contabilidad en el siglo XX el que hizo un fuerte énfasis en la justificación de la contabilidad bajo esta orientación. En su obra maestra, Chambers (1966) no solo cita a Mises con más frecuencia que cualquier otro economista, sino que lo recuerda tanto por su enfoque deductivo como por su multidisciplinariedad. En consecuencia, la discusión de Chambers (1966, pp. 112-115) sobre los ingresos, como el cambio del valor de los activos netos entre dos puntos de tiempo, se basa claramente en Mises (1966, pp. 212-214).

Se podría mencionar a Ronald Coase como otro famoso crítico de la teoría neoclásica $-\mathrm{y}$ especialmente de su uso extensivo de supuestos poco realistas- (Medema, 2008, pp. 432-435), que, sin embargo, era bastante neoclásico en lo que respecta a la contabilidad. En Coase (1990, p. 8), se 
explica cómo él y sus jóvenes colegas de London School of Economics, en la década de 1930, estaban luchando contra los contadores por establecer su nuevo concepto de costo de oportunidad en la contabilidad. En esta, por supuesto, el costo de oportunidad de un activo es su monto de salida, es decir, el precio por el que podría venderse en el mercado; en otras palabras, su valor razonable (Ronen, 2008, p. 186; Buchanan, 1999, pp. 26-29).

En resumen, la visión de la contabilidad financiera de los emisores de estándares se basa en la economía neoclásica. Es más, otras escuelas de economía destacadas no se oponen a esta visión, por lo que no es de extrañar que la contabilidad haya sido víctima del imperialismo neoclásico. En economía, no se disponía de un marco alternativo elaborado.

\subsection{La teoría prospectiva y el enfoque de activos y pasivos}

Los supuestos de la economía neoclásica han sido refutados desde que se formularon por primera vez. En la segunda mitad del siglo XX, un oponente prominente fue el entonces nuevo campo de la economía del comportamiento. Psicólogos y algunos economistas demostraron que las personas reales que toman decisiones concretas no eligen de acuerdo con la teoría de la elección racional. Uno de los resultados más notables de este programa de investigación, que es particularmente relevante para la discusión de los principios contables, fue la teoría prospectiva (Kahneman y Tversky, 1979).

Esta aportó evidencia concluyente de que la mayoría de las personas no actúan de acuerdo con la teoría de la utilidad esperada. En su notable disertación, estos autores argumentan que las valoraciones humanas no se relacionan con los estados finales de riqueza, como en la teoría neoclásica, sino con los cambios en la riqueza. 
[...] la gente normalmente percibe los resultados bien como ganancias o pérdidas, más que un estado final de riqueza o bienestar. Por supuesto, las ganancias y las pérdidas se definen con relación a algún punto de referencia neutral. Este, suele corresponderse con la posición del activo actual, en cuyo caso las ganancias y pérdidas coinciden con los importes reales que se reciben o pagan. (Kahneman y Tversky, 1979, p. 274)

Debido a la función de valoración asimétrica en forma de $S$ asumida en la teoría prospectiva, esto implica que el mero encuadre de ciertos resultados como ganancias o pérdidas puede cambiar el comportamiento de las personas (Biondi y Marzo, 2011, pp. 423 y ss.). Estas “desviaciones de la teoría de la utilidad esperada", añaden Kahneman y Tversky (1979, p. 277), deben conducir a "consecuencias normativamente inaceptables, como inconsistencias, intransitividades, y violaciones del dominio”.

Sin embargo, del modo en que formularon su punto de vista, también se puede inferir algo ligeramente diferente: el enfoque contable del balance, si bien es compatible con la economía neoclásica, contradice la evidencia empírica derivada de la economía del comportamiento. Para los individuos, los estados finales de riqueza no son "portadores de valor" (Kahneman y Tversky, 1979, p. 277). La conducta humana, en otras palabras, no es consistente con el ingreso hicksiano. Este último interrelaciona dos estados de riqueza valorados independientemente (es decir, los valores netos de todos los activos y pasivos), donde la diferencia son los ingresos netos. Esta forma de calcular los ingresos es divergente de lo que muestra la teoría prospectiva para las decisiones humanas reales. Según esta, la posición de los activos, al principio, sirve como un punto de referencia; entonces, las ganancias y pérdidas son "las cantidades de dinero que se obtienen o pagan" (Kahneman y Tversky, 1979, p. 286), y no la diferencia entre la posición actual y una futura (Fennema y Koonce, 2010, p. 6). 
Más bien, la teoría prospectiva es compatible con el enfoque tradicional de la contabilidad de ingresos y gastos. Al calcular con el costo histórico, se constituye un punto de referencia en el balance general: la cantidad original de dinero que se ha pagado por los activos de la firma (Hirshleifer y Teoh, 2009, p. 1078). Estos no se valoran de nuevo cada periodo, sino que su información se acumula hacía adelante. Los ingresos se crean cuando, a partir de esta cantidad de dinero documentada en el balance general, las entradas de recursos son mayores que las salidas (que también pueden incluir disminuciones en el precio original de los activos). Así, la comparación entre la teoría prospectiva y el enfoque de ingresos y gastos nos dice que este último sería una adaptación de la forma en que los humanos evalúan las ganancias y las pérdidas de sus acciones. Podría interpretarse como una traducción del comportamiento humano al nivel de la firma, por medio de las instituciones del cálculo económico y la contabilidad financiera.

La interpretación de la firma como una entidad que "se comporta" de manera similar a los seres humanos reales es compatible con el enfoque presentado y desarrollado por Biondi (2005). En una declaración temprana pero muy concisa que apunta en esta dirección, Sombart (1919, p. 119) argumentó que uno de los propósitos principales de la contabilidad por partida doble es crear una entidad actuante diferenciada. Por medio de la contabilidad, la empresa "asume una existencia separada" y "emerge como un sujeto que realiza actos económicos individuales y que lleva una vida independiente, perdurando más que los individuos" (Sombart, 1919, p. 101). Se aprecia que la contabilidad financiera, de acuerdo con los principios del enfoque de ingresos y gastos, hace que las acciones de esta entidad parezcan estar sujetas a la teoría prospectiva.

No hace falta decir que se debe tener cuidado al dibujar este paralelo. El sistema contable puede establecer la firma como una entidad empresarial, 
pero no debe olvidarse que esta sigue siendo un "campo socioeconómico" cuya representación, organización y gobernanza requieren un análisis específico (Biondi, 2013b, p. 404).

\subsection{El rol del efecto dotación 6 y los costos hundidos}

Richard Thaler (1980) contribuyó con la teoría prospectiva para demostrar más fallas de la teoría económica neoclásica al describir y predecir el comportamiento. Entre otras cosas, se basó en un antiguo resultado de la psicología social (Markowitz, 1952) que Kahneman y Tversky habían integrado en su planteamiento: se ha evidenciado que los individuos humanos evalúan los cambios en su dotación de manera diferente según sean sus pérdidas o ganancias: "El padecimiento que uno experimenta al perder una suma de dinero parece ser mayor que el placer asociado con ganar la misma cantidad" (1979, p. 279). La discusión de Thaler (1980) sobre los costos hundidos y el efecto dotación respalda el argumento de la sección anterior. Aparentemente, quienes toman las decisiones consideran los costos históricos como pérdidas reales o potenciales y, por lo tanto, estos pesan más que los valores de salida que ven como ganancias inciertas.

Según la teoría económica, todos los costos son de oportunidad. Se supone que el costo de cualquier decisión es la alternativa del mayor valor al que se renuncia. Incluso, los gastos de bolsillo, es decir, los desembolsos directos de efectivo, no tienen ningún significado independiente. Como se indicó en la sección 3.1, la descripción de los costos de oportunidad en el balance general es un ideal más o menos explícito del programa del valor razonable. Thaler (1980, p. 44), sin embargo, señala que en la vida real las

\footnotetext{
${ }^{6}$ Corresponde a un sesgo cognitivo, que implica que las personas de manera inconsciente y sistemática tienden a atribuir mayor valor a sus posesiones en comparación con bienes u alternativas similares (N. del T).
} 
decisiones están influenciadas por el efecto dotación. Hace una diferencia de si los costos realmente tienen que hacerse o simplemente consisten en oportunidades (Biondi, 2011b, pp. 1031ss). Para ilustrar este punto, no es lo mismo que alguien elija, por ejemplo, entre una botella de vino y $\$ 5$, a que tome activamente una opción, como pagar \$ 5 por una botella. El hecho de que estén "dotados" con los $\$ 5$ hace a los individuos más reacios a elegir la botella de vino, aunque, desde el punto de vista de la teoría de la utilidad esperada, estas decisiones serían las mismas.

Thaler (1980, p. 44) sostiene que esta observación puede explicarse mediante la teoría prospectiva. A partir del punto de referencia, es decir, de la dotación inicial de activos del actor, los gastos de bolsillo se consideran pérdidas ( $y$, por lo tanto, se sienten intensamente), mientras que los costos de oportunidad se consideran ganancias potenciales que no se tendrán (y, por lo tanto, se perciben de manera más suave). Esto explica por qué estos son mayores que los costos de oportunidad.

Obviamente, estos "gastos de bolsillo" son solo un nombre diferente para los “costos históricos". Estos documentan en el balance general en qué se ha invertido en la empresa hasta ahora. También podrían denominarse “dotación” de la empresa. Entonces, aunque el efecto referido no debería influir en la toma de decisiones, según la teoría neoclásica, esto es importante en las decisiones humanas reales. En este sentido, los principios contables tradicionales no hacen más que aceptar este hecho empírico y trasladarlo al nivel de la firma. Desde la discusión de Thaler (1980) sobre los costos hundidos subraya este paralelo, él declara explícitamente: "La teoría económica implica que solo los costos y beneficios incrementales deberían afectar las decisiones. Los costos históricos deberían ser irrelevantes" (Thaler, 1980, p. 47, énfasis cambiado). 
Basándose en la observación del comportamiento humano, el autor sugiere que la teoría económica no es descriptiva en este aspecto; en cambio, ofrece una hipótesis alternativa. Los costos en los que se ha incurrido en el pasado no son irrelevantes para el presente: "Pagar por el derecho a usar un bien o servicio aumentará la tasa de utilización del bien, ceteris paribus. Esta hipótesis se denominará efecto del coste hundido" (Thaler, 1980, p. 47).

Curiosamente, Thaler (1980) se basa en metáforas tomadas de la contabilidad cuando explica este efecto. Los costos hundidos, dice, no se sienten como un dolor en el momento en que se incurren. En cambio, se memorizan en el "sistema de cuentas psíquicas del individuo" hasta que llega el momento en que se acumulan los ingresos correspondientes (Thaler, 1980, p. 48; Thaler, 1999, pp. 190-192; Okada, 2001). Solo entonces se siente la ganancia o el dolor neto. Utiliza el ejemplo de una familia que paga $\$ 40$ por boletos de béisbol. Sostiene que no se apreciará dolor ni placer en el momento de la compra y únicamente, cuando llegue el día del juego, habrá una comparación entre los $\$ 40$ y el beneficio derivado de ver el juego con la familia sintiendo un "placer neto" (Thaler, 1980, p. 49). Las similitudes entre sus hallazgos y la contabilidad tradicional son tan evidentes que Thaler no puede dejar de reconocerlas (ver también Shafir y Thaler, 2006; Fennema y Koonce, 2010, pp. 10 y ss.). El proceso del costo histórico en la contabilidad financiera no ignora los costos hundidos, como supondría la teoría de la utilidad esperada, sino que busca recuperarlos en el tiempo, de manera que crea una interdependencia a través de periodos.

Se ha argumentado que el efecto de la dotación y, por tanto, los costos hundidos desaparecen con la experiencia del mercado (List, 2003). Si este fuera el caso, dichos conceptos se referirían a una anomalía del comportamiento que solo se podría encontrar en consumidores ( $\sin$ 
experiencia), no en la vida empresarial. Por lo tanto, sería difícil rastrear los principios de contabilidad, que regulan las acciones comerciales, hasta este efecto. Sin embargo, en un estudio reciente, Apicella et al. (2014) han establecido la relación inversa. Según un experimento que realizaron con personas cazadoras-recolectoras aisladas (los hadzabe bosquimanos del norte de Tanzania), los sujetos sin exposición previa al mercado no exhiben el efecto de dotación, mientras que aquellos que han ganado experiencia en él sí lo hacen. Sus hallazgos apoyan empíricamente a Huck et al. (2005), quienes han demostrado que, bajo ciertas condiciones, el mencionado efecto podría proporcionar una ventaja evolutiva en el comercio. De acuerdo con esto, el entorno de negocios podría incluso ser uno de sus detonantes; por tanto, el paralelismo indicado por Thaler entre el comportamiento humano y la contabilidad parece estar aún más que justificado.

\subsection{La teoría prospectiva y el conservadurismo}

Basu (2009, p. 15) y Dickhaut et al. (2010, p. 243), en su discusión sobre la relevancia de la neurociencia para la teoría contable, destacan brevemente otro aspecto de la teoría prospectiva. Afirman que la asimetría entre ganancias y pérdidas que se manifiesta en el comportamiento humano recuerda fuertemente el principio contable del conservadurismo, según el cual el contador no anticipa el reconocimiento de las ganancias, sino el de todas las pérdidas (Watts, 2003, p. 208) y se remonta al menos a inicios del siglo XV (Basu, 1997, pp. 7 y ss.). Su consecuencia más conocida es la valoración de acuerdo con "el costo o el valor de mercado, el que sea de menor cuantía”. Aunque esta elección aparentemente quebranta el principio del costo histórico e interfiere con el de correlación de ingresos y gastos (Yamashita, 1966, p. 3), no obstante, se ha integrado en este enfoque del resultado. Mientras que los críticos del conservadurismo han 
enfatizado en su "potencial para distorsionar los resultados debido a la asimetría en el tratamiento de los ingresos y los gastos", y por lo tanto su carácter irracional, sus partidarios a menudo han afirmado que es simplemente una cuestión de prudencia (Harris et al., 1994, p. 191). Entre otras cosas, evita que las empresas distribuyan demasiados dividendos (Watts, 2003, p. 213).

Sin embargo, parece probable que el conservadurismo sea más que un mero dispositivo de prudencia. Como muestran las pruebas de la teoría prospectiva, las personas generalmente evalúan las ganancias y las pérdidas de manera diferente. Barton et al. (2014), por ejemplo, han encontrado que los inversores reaccionan asimétricamente a la obtención de buenas o malas noticias. Las pérdidas son más significativas que las ganancias y, por lo tanto, parece sensato tratarlas de modo diferenciado también en la contabilidad financiera, exigiendo que estas se reconozcan en la cuenta de resultados rápidamente. En síntesis, este principio contable enmarca la información que reciben los accionistas y los gerentes de una empresa con respecto a las ganancias y pérdidas, de la misma manera que lo hacen los humanos comunes en sus decisiones cotidianas.

\section{La racionalidad ecológica de los principios contables tradicionales}

\subsection{Racionalidad ecológica y constructivista}

A primera vista, los resultados del análisis son hasta ahora contradictorios. No se puede negar que hay buenas razones para que los emisores de normas se orienten hacia la economía neoclásica. Muchos comentaristas competentes consideran a la contabilidad como una institución central de la economía de mercado y el modelado de las leyes económicas de este es el propósito principal de la escuela neoclásica, no de la economía del comportamiento, o al menos no en la misma medida. Uno de los 
principales objetivos de los economistas de esta última tradición parece incluso ser la crítica de los supuestos poco realistas que tienen que hacer sus colegas neoclásicos para poder deducir estas leyes (Smith, 2005, p. 144). Sin embargo, en esta discusión se ha demostrado que los principios contables tradicionales están más cerca de la economía del comportamiento que de la economía neoclásica. Existe un paralelo entre la forma habitual de practicar la contabilidad y el modo en que los humanos se comportan.

Los resultados contrarios a la intuición corren el riesgo de ser descartados por arbitrarios. A diferencia del enfoque del balance, que puede respaldarse con la economía neoclásica, los principios del enfoque de ingresos y gastos no pueden deducirse simplemente de un sistema teórico coherente. Existe un paralelo con la teoría prospectiva, pero hasta ahora esto es solo un hallazgo empírico.

En este capítulo 4 se explica por qué es cierto que las reglas contables tradicionales no se ajustan a los supuestos neoclásicos, sino a la conducta descrita por la economía del comportamiento. El argumento se basa en la distinción entre dos formas de racionalidad, realizada sobre todo por Vernon Smith (2003; 2008), pero anticipada claramente por Menger (1892), Hayek (1967a; 1967b; 1978) y Simon (1981; 1990).

La primera forma es la racionalidad consciente, que Smith llama constructivista. Se aplica cuando un resultado se produce intencionadamente por la acción de un agente o un organismo que actúa. Detrás de esta racionalidad está la idea de que "todas las instituciones valiosas fueron y deberían ser creadas por procesos deductivos derivados de la razón humana" (Smith, 2008, p. 26). La segunda forma es la racionalidad ecológica. Este autor sostiene que, en los contextos sociales, la racionalidad de un resultado no es el producto de un plan estructurado, sino la consecuencia involuntaria de acciones e interacciones 
descentralizadas de individuos desprevenidos. Entonces, no se trata del diseño humano, sino del entorno donde se toman las decisiones y se despliegan sus efectos en un proceso de autocoordinación.

Siguiendo algunas observaciones de Waymire y Basu (2007, p. 93) y Basu (2015, p. 246), se argumentará que los principios contables tradicionales son una institución del tipo racional ecológico. Nunca se han diseñado racionalmente desde cero; sino que han sido hasta ahora el resultado de la evolución cultural. Parece que han garantizado mejor que otros principios la supervivencia de las empresas que los aplican, especialmente en tiempos de problemas económicos.

En la sección 4.2 se explica en detalle qué se entiende por principios contables racionales ecológicamente. El argumento no es que se desarrollen sin ninguna interferencia de la investigación, la ley o incluso la emisión de estándares. Se trata más bien de que el proceso de encontrar parámetros contables de alta calidad debe estar abierto a la refutación empírica, es decir, a ensayo y error.

En el apartado 4.3 se describen algunas hipótesis sobre por qué los principios contables tradicionales han evolucionado del modo en que lo han hecho. Este paso es esencial si se quiere convencer a los políticos, los investigadores y los reguladores contables de estos argumentos en favor de una mayor participación de la racionalidad ecológica en el desarrollo de estándares contables. El tema central es demostrar ex post cómo se constituye exactamente la idoneidad de estos principios evolucionados ecológicamente. Se mostrará que son ventajosos para la empresa considerada individualmente, pero también que son compatibles con el funcionamiento de la economía de mercado en su conjunto. En la sección 4.4, finalmente, se señala hasta qué punto el enfoque constructivista del FASB y el IASB puede ser criticado con base en estos hallazgos. 


\subsection{La contabilidad y sus principios como una institución cultural que evoluciona}

Actualmente, en los libros de texto de contabilidad en los Estados Unidos, la historia de la contabilidad financiera comienza habitualmente en 1934, con la formación de la Comisión de Bolsa y Valores (Securities and Exchange Commission, SEC), y su delegación del establecimiento de normas contables en organismos privados (Sunder, 2005, p. 373; Waymire y Basu, 2007, p. 4; Basu, 2015, p. 249). El cambio hacia estándares autorizados, promulgados por escrito y de aplicación forzosa, se aceleró a principios de la década de 1970 después de que se lanzó el proyecto de Marco Conceptual del FASB. Biondi (2011a, p. 2) incluso habla de una "revolución contable". En consecuencia, los investigadores de la disciplina "utilizan casi exclusivamente teorías implícitas del diseño intencional para analizar las prácticas contables, ya sea que estén integradas en los marcos conceptuales de los reguladores o en los análisis estáticos comparativos de los académicos" (Waymire y Basu, 2007, pp. 1 y s.). En otras palabras, se utiliza una visión constructivista. Los principios contables se consideran el producto de deliberaciones conscientes y procesos de toma de decisiones políticas. Se supone que los emisores de normas pueden diseñar reglas contables de forma racional.

Debe agregarse que la política del FASB y el IASB de converger y apuntar a la armonización internacional de las prácticas contables, criticada por Sunder (2010), es una consecuencia natural de su enfoque constructivista general. Si los emisores esperaran a la competencia entre diferentes estándares para mostrar cuál de ellos evoluciona como el más robusto, abandonarían implícitamente su afirmación de que es posible diseñar reglas y principios contables de manera racional y, por lo tanto, perderían una parte importante de su razón de ser. 
Es cierto, especialmente desde que estalló la crisis financiera en 2007, pero incluso antes, que una cantidad creciente de críticos se habían quejado de las fallas en los estándares contables diseñados. En particular, se ha dicho que el valor razonable es responsable de una mayor fragilidad financiera de las compañías y los bancos y se le ha culpado de exacerbar las burbujas del mercado (Boyer, 2007; Allen y Carletti, 2008; Plantin et al., 2008; Dichev, 2008, p. 466; Yuan y Liu, 2011, pp. 18-28). Las políticas de los reguladores contables han sido severamente criticadas, y también el hecho de que el proceso de establecimiento de normas se haya delegado en organismos privados (Perry y Nölke, 2006). Sin embargo, la visión constructivista según la cual los principios contables son y deben proyectar conscientemente ha sido cuestionada por unos pocos comentaristas. Sunder (2005, p. 373) se preocupa: “A principios del siglo XXI, pocas personas parecen estar al tanto de la norma social, la convención o el enfoque del derecho consuetudinario de la era anterior, y tal enfoque apenas tiene defensores".

Sunder (2005, p. 372; 2010, p. 104) argumenta que el mundo de la contabilidad no tenía menos orden en los días previos a que se establecieran estándares autorizados. Había normas comerciales y profesionales que se habían desarrollado con el tiempo y que regulaban la contabilidad de una manera más informal, lo cual también es sostenido por Littleton (1953, p. 2), Byrne (1965, p. 107), Huerta de Soto (2012) y Waymire y Basu (2007, pp. 1 y ss.).

Sin duda, el argumento no es que el diseño y la evolución de las normas sociales sean mutuamente excluyentes y que, por lo tanto, nadie haya delineado nunca los principios contables tradicionales (Sunder, 2005, pp. 375 y ss.). La dependencia total de los estándares confeccionados o solo de las normas puramente evolucionadas puede no producir resultados óptimos (Biondi et al., 2012, pp. 129ss). Evidentemente, los tratados de 
algunos escritores famosos, como Luca Pacioli o Jacques Savary, y, asimismo, importantes textos legislativos, como el Code de Commerce francés, el Allgemeine Landrecht prusiano o el Joint Stock Companies Act británico de 1856 influyeron en las prácticas contables durante siglos. El punto es que, a lo largo de la historia, numerosos principios contables que se han diseñado conscientemente se han puesto a prueba, pero solo unos pocos resistieron el paso del tiempo y llegaron hasta nuestros días. El proceso de ensayo, error y competencia entre diferentes regímenes contables permitió eliminar aquellos parámetros que afectaban negativamente tanto la salud de las empresas que los aplicaban como el bienestar general, de manera que los principios que permanecían se constituían en una manera de garantizar la supervivencia de las compañías y su entorno económico (Byrne, 1965, p. 109; Salin, 2010, p. 58; Basu, 2015, p. 253).

La investigación de Hoffmann y Detzen (2013) puede evidenciar lo que se quiere decir con este punto. Con la única excepción del periodo posterior a la Segunda Guerra Mundial, en Alemania, la valoración discrecional siempre se hizo popular durante los auges económicos. Sin embargo, en las recesiones posteriores, la regulación laxa y las sobrevaloraciones resultantes se identificaron usualmente como catalizadores del desarrollo exuberante durante la fase de expansión, lo que dio lugar a varias revisiones de la ley comercial hacia los costos históricos. Como lo expresan los mencionados autores, la legislación ha sido "inducida por las crisis" en el sentido de que los eventos socioeconómicos influyeron considerablemente en la regulación contable. Littleton (1933, p. 277) presenta un caso similar para Gran Bretaña, donde describe la secuencia habitual de eventos en el siglo XIX de la siguiente manera: "Una crisis financiera, grandes fracasos comerciales, un nuevo estatuto de quiebras" (ver también Waymire y Basu, 2011). 
Según Walker (1992), Zeff (2007) y Markarian (2014), algo muy similar sucedió en Estados Unidos, donde la SEC, en 1934, partió con un punto de vista muy conservador sobre la contabilidad financiera debido a las conexiones que algunos de sus comisionados, sobre todo Robert Healy, vieron entre los informes opulentos hechos durante el auge de la década de 1920 y la gravedad de la siguiente caída del mercado de valores de 1929. Es interesante notar que el texto que hizo época en aquel entonces, Paton y Littleton (1940), reflejaba este punto de vista claramente (Biondi, 2013a, p. 363; Markarian, 2014, p. 46). La importante influencia que tuvo en el pensamiento y la práctica contable durante las décadas siguientes, también puede verse como el efecto intermedio de un proceso de ensayo y error. Fue una consecuencia indirecta de la crisis anteriormente señalada.

\section{3. ¿Es posible una reconstrucción racional?}

La institución de la contabilidad ha evolucionado en un proceso muy largo. Nadie decidió sobre la cuestión sobre la forma de llevar registros es la mejor o la más exitosa. En cambio, la evolución cultural ha demostrado que los principios contables han resistido la prueba del tiempo. Sin embargo, como consecuencia del énfasis casi exclusivo en la racionalidad constructivista de la investigación contable, "no entendemos prácticamente nada acerca de cómo esta importante institución evoluciona espontáneamente" (Waymire y Basu, 2007, p. 2).

Pero, aunque no sea posible determinar por qué exactamente las normas contables se desarrollaron de la manera en que lo hicieron, como se comentó anteriormente, es claro que estas no fueron diseñadas intencionalmente por nadie y tan solo se puede reconstruir racionalmente algunas de las razones de su evolución (Smith, 2003, p. 470).

De especial interés es la pregunta planteada al comienzo de este capítulo: ¿por qué perduraron esos principios contables que se asemejan a la 
conducta observada por la economía del comportamiento, y no otros que son más compatibles con los supuestos de la economía neoclásica? ¿En qué consiste su especificidad?

Desafortunadamente, no se puede dar una respuesta precisa, al menos no todavía. Las normas sociales, como observa acertadamente Sunder (2005, p. 371), "no dejan huella en el registro público". Solo se puede conjeturar que el comportamiento particular que cumple con los supuestos de la teoría de la elección racional no es necesariamente el que prevalece con el paso del tiempo, ni para los humanos en la evolución de las especies ni para las empresas en el contexto social de la economía de mercado. La racionalidad individual puede ser importante en algunos casos, pero no tiene por qué ser el único factor de éxito, ni siquiera el más significativo. Un ejemplo de esto son los costos hundidos. La mayoría de nosotros conoce y comprende la razón del argumento de la economía estándar sobre por qué estos costos no deberían influir en nuestras decisiones. No obstante, todos hemos cometido y seguimos cometiendo el "error" de no ignorar los costos pasados en lo que hacemos, especialmente en los momentos en que nos olvidamos del citado argumento. ¿Significa esto que todos somos irracionales? ¿No podría ser que, por algún motivo aún desconocido, aquellos de nuestros antepasados que no ignoraron los costos hundidos tenían una ventaja sobre aquellos que presumiblemente fueron más racionales? Si este fuera el caso, el hecho de que las normas contables tradicionales impliquen el uso de costos hundidos en forma de costos históricos podría indicar que esta regla contiene un conocimiento tácito del que aún no tenemos una idea clara. Si la vida se ve como un proceso de ensayo y error, por ejemplo, es necesario que los actores puedan evaluar si lo que han hecho fue equívoco o no, y qué tan dañino fue esto. Entonces, se necesita tener una idea de lo que se ha perdido al seguir un camino especial de acción. Los costos hundidos proporcionan este tipo 
de información, en la medida en que no pueden recuperarse, dan una pista a los tomadores de decisiones sobre la magnitud de sus errores o, en caso de que se vean compensados por ganancias, sobre el alcance de su logro. Por lo tanto, pueden servir como guías para decisiones futuras exitosas.

El caso parece más claro para el conservadurismo. No es inconcebible en absoluto que, desde una perspectiva evolutiva, sea un código de conducta prudente poner más énfasis en evitar el dolor que en obtener placer. No hace falta decir que la supervivencia es una precondición para disfrutar de este y, por lo tanto, es lo más importante. Una regla contable que haga que el empresario sienta las pérdidas antes que las ganancias lo inducirá igualmente a evitar los riesgos asociados más que si no tuviera este parámetro (Watts, 2003, p. 213). Puede ser una pauta que no garantiza la maximización a corto plazo, pero, en cambio, podría mejorar la probabilidad de beneficios positivos y, por lo tanto, la continuidad de la empresa comercial a lo largo del tiempo (Alchian, 1950, p. 218; Waymire y Basu, 2011, p. 218).

No hace falta decir que esta discusión solo contiene sugerencias y conjeturas sobre por qué las normas contables evolucionadas se han convertido en lo que son. Sin embargo, debería quedar claro que se puede argumentar que son ecológicamente racionales. Aunque todavía no comprendemos completamente cómo y por qué funcionan, podemos ver que una desviación de ellos puede conducir a problemas graves, especialmente durante los auges y las depresiones económicas. Por eso reaparecen regularmente en la agenda, a pesar de que aparentemente no son racionales desde un punto de vista constructivista. Lo que queda por hacer -y esta es la mayor parte del trabajo- es reconstruir esta ecología racional con más detalle. 
Parece especialmente prometedor a este respecto analizar hasta qué punto los diferentes principios contables encajan en el marco general de la economía de mercado. ¿Qué diferencia supone para el entorno en su conjunto si las empresas aplican el enfoque del balance o el enfoque de ingresos y gastos en la contabilidad? La visión de Hayek (1945) sobre el funcionamiento del sistema de precios podría servir como punto de partida para el programa de investigación correspondiente. Él argumentó que la teoría neoclásica le da la vuelta a la lógica del sistema de precios. Este no presupone cantidades extraordinarias de conocimiento o racionalidad por parte de los participantes del mercado; al contrario, genera conocimiento sobre las limitaciones relativas en la sociedad. Cada individuo solo necesita el "conocimiento de las circunstancias particulares de tiempo y lugar" (Hayek, 1945, p. 521), no más. Por lo tanto, la información privada es la entrada y la información pública es la salida del proceso de mercado.

Esta visión respalda el enfoque tradicional de ingresos y gastos (Basu y Waymire, 2010, pp. 138 y ss.). Se podría argumentar que no es necesario y ni siquiera significativo que el balance general contenga datos de interés público. Este tipo de información solo es generada por el proceso de mercado, y las entradas de este son las declaraciones privadas de las circunstancias de tiempo y lugar.

Esto es exactamente lo que revelan las cifras basadas en la contabilidad de costos históricos: información nueva y privada. Comunican la cantidad de dinero que ha pagado una empresa por su activo en momentos específicos del pasado, y las partidas del resultado correspondientes nos dicen cuántos beneficios se obtuvieron por estas transacciones. Cómo se hicieron sigue siendo su secreto. Posiblemente, nadie más hubiera pagado estos montos por dichos activos y conseguido los beneficios asociados. Se trata, entonces, de reflejar acciones reales de la empresa, en las que esta 
consideró su "conocimiento específico de las circunstancias particulares de tiempo y lugar". Por lo tanto, los estados de resultados basados en costos históricos pueden servir como una entrada de información para el proceso de mercado.

Sin embargo, no se genera nueva información cuando, como en la contabilidad del valor razonable, el valor de mercado de un activo se muestra en el balance general y sus variaciones en el estado de resultados (Schildbach, 2015, pp. 79 y ss.). Estas son las salidas del proceso del mercado, es decir, de las acciones de los otros participantes, no una entrada de información de ningún tipo. Desde este punto de vista, el ingreso hicksiano, el ideal de los partidarios del enfoque del balance no aporta novedad, sino que presupone que la información necesaria ya la proporciona el mercado (Sunder, 2013, p. 1).

El argumento según el cual no tiene sentido exigir que los balances contengan información de interés público no implica que la información proporcionada por el mercado deba excluirse categóricamente estos. El principio del conservadurismo con su regla de la menor cuantía entre el costo y el valor de mercado es un buen ejemplo en este caso.

En general, se puede decir que la actitud del participante individual en el mercado hacia el riesgo, las pérdidas y las ganancias, ya sea "racional" o no, es simplemente parte de la información privada que ingresa al proceso del mercado. No hay ninguna razón por la que la posibilidad de coordinar los planes de los participantes deba depender de la ansiedad con la que calculan sus beneficios. Los planes conservadores se pueden gestionar de la misma manera que los optimistas o realistas. El resultado del mercado probablemente difiera, pero no su eficiencia.

Pero incluso la regla de la menor cuantía entre el costo y el valor de mercado, aunque depende en parte de la información proporcionada por 
este último, puede conciliarse fácilmente con la visión de Hayek del sistema de precios. Si un activo se ajusta a su valor de mercado, los cambios correspondientes en el estado de resultados aún reproducen datos nuevos y privados. El punto es que la influencia de este ajuste no solo depende de la reducción actual del precio en sí, sino también del valor en libros anterior del activo. En un sistema de contabilidad de costos históricos, este valor puede diferir considerablemente entre empresas, y lo mismo ocurre con las cifras de beneficios correspondientes. En consecuencia, la citada regla podría influir en el estado de resultados de las empresas de maneras completamente diferentes y, por lo tanto, informar estas cifras no es redundante, sino que proporciona nueva información al proceso del mercado.

\subsection{Límites de la aproximación constructivista avalada por los emisores de estándares}

Los argumentos presentados en la última sección implican que se debe reconsiderar la tendencia de alejarse del enfoque de ingresos y gastos hacia el del balance. Hay razones por las que los principios tradicionales se desarrollaron de la forma en que lo han hecho. Sustituyéndolos por otros, quizá los emisores de estándares pueden basarlos en el sistema coherente de la economía neoclásica. Sin embargo, también corren el riesgo de comprometer la solidez financiera de las empresas y, contrariamente a su intención, disminuir la utilidad de la información que las cifras contables envían al mercado.

Debe quedar claro, sin embargo, que la defensa de los principios contables tradicionales y la crítica del enfoque del balance no apunta a un simple retorno a los primeros, si bien estos han sido la consecuencia de un largo proceso evolutivo y parecen ecológicamente racionales. Nadie sabe a dónde se conducirá la institución de la contabilidad en las próximas 
décadas y qué principios serán necesarios en la búsqueda de estándares de alta calidad que estuvieran sujetos al desarrollo de ese camino.

Lo que se desprende de los argumentos esbozados en el presente documento es más bien una crítica al proceso actual de emisión de estándares. El establecimiento monopolístico y la aplicación de parámetros uniformes en casi todo el mundo destruyen la competencia entre los diferentes principios contables, no solo a nivel nacional, sino también a nivel internacional. Como señalan Jamal y Sunder (2014, p. 383) en este contexto, "[...] los monopolios no son conocidos por su innovación”. La racionalidad ecológica ha sido rechazada como fuente de sabiduría porque el proceso evolutivo de ensayo y error ha sido reprimido como fuente de información en términos de Alchian (1950, p. 219); en cambio, la racionalidad constructivista ha ocupado su lugar. Hay al menos tres áreas donde esta orientación del FASB y el IASB restringe la generación y procesamiento de conocimiento nuevo y potencialmente importante sobre el tema.

Primero, ignora las consecuencias de errores pasados, es decir, la evidencia histórica del dominio evolutivo del enfoque de ingresos y gastos: su racionalidad ecológica. El ensayo y el error no pueden funcionar si no se permite clasificar los intentos como éxitos o fracasos. De esta manera, se provocan nuevas y dolorosas refutaciones empíricas del enfoque del balance y se prohíbe cualquier avance.

En segundo lugar, al aspirar a la uniformidad y al pretender que su punto de vista sea obligatorio en todo el mundo, los emisores de estándares descartan la posibilidad de beneficiarse de la competencia entre diferentes regímenes contables. Para que esta pueda funcionar como un "procedimiento de descubrimiento" (Hayek, 2002), los resultados obtenidos con un sistema de reglas deben ser comparables a los que habrían producido cursos de acción diversos. Sin competencia entre 
diferentes sistemas contables, no se puede poner en práctica ninguna reglamentación alternativa. Como consecuencia, a los reguladores les resulta mucho más difícil identificar avances -o regresiones- en los principios contables (Sunder, 2010, p. 106; Madsen, 2013, pp. 871 y ss.).

En tercer lugar, ya Baxter (1953, p. 425) advirtió contra los peligros de las reglas obligatorias, incluso cuando son establecidas por benevolentes emisores de estándares, para el progreso de la investigación contable. Él argumentó que los "debates candentes sobre cuestiones como la depreciación, la medición de ingresos, la valoración de activos y los efectos de los cambios en los niveles de precios" ilustran vívidamente lo difícil que es saber "dónde está la verdad" en el diseño de la regulación. Cuando existen lineamientos forzosos, estas cuestiones y otras son resueltas por la autoridad y el discurso cambia del examen crítico de los méritos de las reglas y las prácticas contables alternativas a la reproducción y la discusión de planteamientos preestablecidos. Es de temer que esto disminuya el potencial innovador sobre aspectos centrales, como la mejora y reforma de los estándares actuales. Además, la investigación contable se vuelve menos atractiva para los estudiantes talentosos porque se reemplaza el pensamiento abstracto y fundamental por la reflexión superficial en blanco y negro (Sunder, 2010, pp. 108 y ss.).

Un posible argumento que matice estos puntos podría ser que los estándares solo son obligatorios para la contabilidad financiera pero no para la de gestión, y que, por lo tanto, no es necesario que los administradores tomen sus decisiones sobre la base del enfoque regulado del balance. Sin embargo, si las empresas se ven limitadas a generar datos que no necesitan y a utilizarlos en sus procesos internos, los costos aumentaran ampliamente con pocos beneficios compensatorios. Entonces, el proceso de emisión de estándares sería superfluo y un uso de recursos cuestionable. 


\section{Conclusión}

Está fuera del alcance de este estudio presentar propuestas elaboradas para la reforma del proceso de emisión de estándares. Ciertamente, lo que Dye y Sunder (2001) plantearon para la discusión facilitaría una mayor racionalidad ecológica en el desarrollo de normas contables de alta calidad. Si se permitiera que diferentes estándares operaran uno al lado del otro, tanto dentro como a través de las comunidades legales, la competencia entre ellos podría funcionar como un procedimiento de descubrimiento. Entonces, las cualidades relativas de cada estándar podrían observarse directamente y compararse; su evaluación no tendría que depender de un mero razonamiento de sillón.

Lo que ha demostrado esta investigación es que, independientemente de la forma concreta de implementación, hay algo que ganar al abrir el proceso de emisión de estándares a la evolución cultural. Hay algo detrás de los principios tradicionales de contabilidad, aunque nunca se han diseñado propositivamente desde cero.

Se ha demostrado que el enfoque de ingresos y gastos y, especialmente, los principios del costo histórico y el conservadurismo guardan una gran semejanza con el comportamiento humano, como lo evidencia la teoría prospectiva. Ya sea que esto sea racional o no, las personas no ignoran los costos hundidos y valoran las ganancias y pérdidas de manera distinta. Además, evalúan los resultados de sus acciones como cambios relativos a un punto de referencia, no como la diferencia entre dos estados de riqueza valorados individualmente.

También, se ha probado que no necesariamente tiene que ser un problema cuando la contabilidad se lleva a cabo de acuerdo con principios que no se ajustan a los supuestos de la economía neoclásica. Incluso, estos parecen aumentar las posibilidades de que sus usuarios permanezcan en el 
negocio. Así mismo, el hecho de que el enfoque de ingresos y gastos incorpore principalmente información privada lo convierte en compatible con la perspectiva del proceso de mercado del sistema de precios.

\section{Referencias}

Alchian, A. A. (1950). Uncertainty, evolution, and economic theory. Journal of Political Economy, 58(3), 211-221. https://doi.org/10.1086/256940

Allen, F. y Carletti, E. (2008). Mark-to-market accounting and liquidity pricing. Journal of Accounting and Economics, 45(2-3), 358-378.

https://doi.org/10.1016/j.jacceco.2007.02.005

Apicella, C. L., Azevedo, E. M., Christakis, N. A. y Fowler, J. H. (2014). Evolutionary origins of the endowment effect: Evidence from hunter-gatherers. American Economic Review, 104(6), 1793-1805.

Barlev, B. y Haddad, J. R. (2003). Fair value accounting and the management of the firm. Critical Perspectives on Accounting, 14, 383-415.

Barth, M. E. (2006). Including estimates of the future in today's financial statements. Accounting Horizons, 2O(3), 271-285.

Barton, J., Berns, G. S. y Brooks, A. M. (2014). The neuroscience behind the stock market's reaction to corporate earnings news. The Accounting Review, 89(6), 1945-1977. https://doi.org/10.2308/accr-50841

Basu, S. (1997). The conservatism principle and the asymmetric timeliness of earnings. The Journal of Accounting an Economics, 24, 3-37.

Basu, S. (2009). Conservatism research: Historical development and future prospects. China Journal of Accounting Research, 2(1), 1-20. https://doi.org/10.1016/S17553091(13)60007-6

Basu, S. (2015). Is there a scientific basis for accounting? Implications for practice, research, and education. Journal of International Accounting Research, 14(2), 235-265.

Basu, S. y Waymire, G. B. (2010). Sprouse's what-you-may-call-its: fundamental insight or monumental mistake? Accounting Historians Journal, 37(1), 121-148. 
Baxter, W. T. (1953). Recommendations on accounting theory. En W. T. Baxter y S. Davidson (eds.), Studies in accounting theory (pp. 414-427). Sweet and Maxwell.

Beaver, W. H., y Demski, J. S. (1979). The Nature of income measurement. The Accounting Review, 54(1), 38-46.

Biondi, Y. (2005). The Firm as an Entity: Management, Organization, Accounting [documento de trabajo n. ${ }^{\circ} 46$ ]. Universita degli Studi di Brescia. http://dx.doi.org/10.2139/ssrn.774764

Biondi, Y. (2011a). The pure logic of accounting: A critique of the fair value revolution. Accounting, Economics, and Law, 1(1), 1-49. https://doi.org/10.2202/2152$\underline{2820.1018}$

Biondi, Y. (2011b). The problem of social income: The entity view of the cathedral. Seattle University Law Review, 34(4), 1025-1047.

Biondi, Y. (2013a). Accounting, economics, and law of the enterprise entity. A. C. Littleton and the German-American connection. En Y. Biondi y S. Zambon (eds.), Accounting and business economics. Insights from national traditions (pp. 363386). Routledge.

Biondi, Y. (2013b). The governance and disclosure of the firm as an enterprise entity. Seattle University Law Review, 36(2), 391-416.

Biondi, Y. y Marzo, G. (2011). Decision making using behavioral finance for capital budgeting. En H. K. Baker y P. English (eds.), Capital budgeting valuation. financial analysis for today's investment projects (pp. 421-444). John Wiley \& Sons.

Biondi, Y., Jamal, K., Ohlson, J. A., Sunder, S. y Tsujiyama, E. (2012). Some conceptual tensions in financial reporting. Accounting Horizons, 26(1), 125-133. https://doi.org/10.2308/acch-50087

Boyer, R. (2007). Assessing the impact of fair value upon financial crises. Socio-Economic Review, 5(4), 779-807. https://doi.org/10.1093/ser/mwmo18

Braun, E. (2014). Finance behind the veil of money. Liberty.me.

Brief, R. P. (1982). Hicks on accounting. The Accounting Historians Journal, 9(1), 91-101.

Bromwich, M., Macve, R. H. y Sunder, S. (2010). Hicksian income in the conceptual framework. Abacus, 46(3), 348-376.

Revista Activos

ISSN: 0124-5805 | e-ISSN: 2500-5278 | DOI: https://doi.org/10.15332/25005278

Vol. 19 N. ${ }^{\circ} 1$ | enero-junio de 2021 
Buchanan, J. M. (1999). The collected works of James M. Buchanan. Volume 6: Cost and choice. Liberty Fund.

Byrne, G. R. (1965). To what extent can the practice of accounting be reduced to rules and standards? En M. Moonitz y A. C. Littleton (Eds.), Significant accounting essays (pp. 103-115). Prentice-Hall.

Canziani, A. (2013). Accounting and "Economia Aziendale" in Italy, 1911 afterward. En Y. Biondi y S. Zambon (eds.), Accounting and business economics. Insights from national traditions (pp. 69-101). Routledge.

Chambers, R. J. (1966). Accounting, evaluation and economic behavior. Prentice-Hall.

Chiapello, E. (2008). Accounting at the heart of the performativity of economics. Economic Sociology _ the European Electronic Newsletter, 10(1), 12-15.

Coase, R. H. (1990). Accounting and the theory of the firm. Journal of Accounting and Economics, 12(1-3), 3-13. https://doi.org/10.1016/0165-4101(90)90038-6

Dichev, I. D. (2008). On the balance sheet-based model of financial reporting. Accounting Horizons, 22(4), 453-470. https://doi.org/10.2308/acch.2008.22.4.453

Dickhaut, J. (2009). The brain as the original accounting institution. The Accounting Review, 84(6), 1703-1712. https://doi.org/10.2308/accr.2009.84.6.1703

Dickhaut, J., Basu, S., McCabe, K. A., y Waymire, G. B. (2009). Neuroaccounting II: Consilience between accounting principles and the primate brain. http://dx.doi.org/10.2139/ssrn.1336517.

Dickhaut, J. W., Basu, S., McCabe, K. A. y Waymire, G. B. (2010). Neuroaccounting: consilience between the biologically evolved brain and culturally evolved accounting principles. Accounting Horizons, 24(2), 221-255.

Dillard, J. (2008). A political base of a polyphonic debate. Critical Perspectives on Accounting, 19(6), 894-900. https://doi.org/10.1016/j.cpa.2007.02.005

Dye, R. A. y Sunder, S. (2001). Why not allow FASB and IASB to compete in the US? Accounting Horizons, 15(3), 257-271.

Fennema, M. G. y Koonce, L. (2010). Mental accounting in financial reporting and voluntary disclosure. Journal of Accounting Literature, 29, 1-29. http://dx.doi.org/10.2139/ssrn.1717078 
Ferguson, A. (1767). An essay on the history of civil society. Millar \& Caddel.

Fetter, F. A. (1937). Reformulation of the concepts of capital and income in economics and accounting. The Accounting Review, 12(1), 3-12.

Friedman, M. (1953). The methodology of positive economics. En M. Friedman (ed.), Essays in positive economics (pp. 3-43). University of Chicago Press.

Gaffikin, M. J. (1989). Accounting methodology and the work of R. J. Chambers.Garland Publishing.

Gaffikin, M. J. (2012). Raymond J. Chambers - A personal reflection. Accounting Education, 21(1), 25-39. https://doi.org/10.1080/09639284.2011.618589

Harris, T. S., Lang, M. y Möller, H. P. (1994). The value relevance of German accounting measures: An empirical analysis. Journal of Accounting Research, 32(2), 187-209. https://doi.org/10.2307/2491281

Hatfield, H. R. (1965). An historical defense of bookkeeping. En M. Moonitz y A. C. Littleton (eds.), Significant accounting essays (pp. 3-13). Prentice-Hall. (Original publicado en 1965).

Hayek, F. A. (1935). The maintenance of capital. Economica, 2(7), 241-276. https://doi.org/10.2307/2548607

Hayek, F. A. (1945). The use of knowledge in society. The American Economic Review, 35(4), 519-530.

Hayek, F. A. (1967a). The results of human action, but not of human design. En F. A. Hayek (ed.), Studies in philosophy, politics and economics (pp. 96-105). University of Chicago Press.

Hayek, F. A. (1967b). Rules, perception and intelligibility. En F. A. Hayek (ed.), Studies in philosophy, politics and economics (pp. 43-65). University of Chicago Press.

Hayek, F. A. (1978). The errors of constructivism. En F. A. Hayek (ed.), New studies in philosophy, politics, economics and the history of ideas (pp. 3-22). Routledge \& Paul.

Hayek, F. A. (2002). Competition as a discovery procedure. The Quarterly Journal of Austrian Economics, 5(3), 9-23.

Hicks, J. R. (1946). Value and capital (2. ${ }^{\mathrm{a}}$ ed.). Clarendon. 
Hirshleifer, D. y Teoh, S. H. (2009). The psychological attraction approach to accounting and disclosure policy. Contemporary Accounting Research, 26(4), 1067-1090. https://doi.org/10.1506/car.26.4.3

Hitz, J. M. (2007). The decision usefulness of fair value accounting - a theoretical perspective. European Accounting Review, 16(2), 323-362. https://doi.org/10.1080/09638180701390974

Hoffmann, S. y Detzen, D. (2013). The regulation of asset valuation in Germany. Accounting History, 18(2), 367-389.

Huck, S., Kirchsteiger, G. y Oechssler, J. (2005). Learning to like what you have explaining the endowment effect. The Economic Journal, 115(505), 689-702.

Huerta de Soto, J. (2012). Money, bank credit, and economic cycles ( $3 .^{\mathrm{a}}$ ed.). Mises Institute.

Ijiri, Y. (2005). US accounting standards and their environment: A dualistic study of their 75-years of transition. Journal of Accounting and Public Policy, 24(4), 255-279. https://doi.org/10.1016/j.jaccpubpol.2005.05.004

Jamal, K., y Sunder, S. (2014). Monopoly versus competition in setting accounting standards. Abacus, 5O(4), 369-385.

Jameson, J. (2005). FASB and the IASB versus J. R. Hicks. Research in Accounting Regulation, 18, 331-334.

Kahneman, D. y Tversky, A. (1979). Prospect theory: An analysis of decision under risk. Econometrica, 47(2), 263-292.

Kirzner, I. M. (1997). Entrepreneurial discovery and the competitive market process: An Austrian approach. Journal of Economic Literature, 35(1), 60-85.

Klamer, A. y McCloskey, D. (1992). Accounting as the master metaphor of economics. The European Accounting Review, 1(1), 145-160.

Kohn, M. (2004). Value and exchange. Cato Journal, 24(3), 303-339.

Koonce, L. y Mercer, M. (2005). Using psychology theories in archival accounting research. Journal of Accounting Literature, 74, 175-214.

List, J. A. (2003). Does market experience eliminate market anomalies? The Quarterly Journal of Economics, 118(1), 41-71. 
Littleton, A. C. (1933). Accounting evolution to 190o. American Institute Publishing Co.

Littleton, A. C. (1953). Structure of accounting theory, American Accounting Association [monografía n. ${ }^{\circ}$ 5]. American Accounting Association.

Madsen, P. E. (2013). The pursuit of high-quality accounting standards. Accounting Horizons, 27(4), 867-876. https://doi.org/10.2308/acch-10368

Markarian, G. (2013). Developments in accounting and business economic thought: Evidence from the United States. En Y. Biondi y S. Zambon (eds.), Accounting and business economics. insights from national traditions (pp. 306-328). Routledge.

Markarian, G. (2014). The crisis and fair values: Echoes of early twentieth century debates? Accounting Historians Journal, 41(1), 35-60.

Markowitz, H. (1952). The utility of wealth. Journal of Political Economy, 6o(2), 151-158.

Mattessich, R. (2013). Accounting theories of the first half of the twentieth century: The genesis of an academic discipline. En Y. Biondi y S. Zambon (eds.), Accounting and business economics. insights from national traditions (pp. 3-35). Routledge.

Medema, S. G. (2008). Ronald Coase as a dissenting economist. Studi E Note Di Economia, 13(3), 427-448.

Menger, C. (1892). On the origin of money. The Economic Journal, 2(6), 239-255.

Mises, L. v. (1920). Die Wirtschaftsrechnung im sozialistischen Gemeinwesen. Archiv für Sozialwissenschaft und Sozialpolitik, 47(1), 86-121.

Mises, L. (1966). Human action. A treatise on economics (3. ${ }^{\mathrm{a}}$ ed.). Regnery.

Okada, E. M. (2001). Trade-ins, mental accounting, and product replacement decisions. Journal of Consumer Research, 27(4), 433-446. https://doi.org/10.1086/319619

Paton, A. W. y Littleton, A. C. (1940). Introduction to corporate accounting standards. American Accounting Association.

Perry, J. y Nölke, A. (2006). The political economy of international accounting standards. Review of International Political Economy, 13(4), 559-586.

Plantin, G., Sapra, H. y Shin, H. S. (2008). Marking-to-market: Panacea or pandora's box? Journal of Accounting Research, 46(2), 435-460.

Revista Activos

ISSN: 0124-5805 | e-ISSN: 2500-5278 | DOI: https://doi.org/10.15332/25005278

Vol. 19 N. ${ }^{\circ} 1$ | enero-junio de 2021 
Rayman, R. A. (2007). Fair value accounting and the present value fallacy: The need for an alternative conceptual framework. The British Accounting Review, 39(3), 211225. https://doi.org/10.1016/j.bar.2007.03.006

Ronen, J. (2008). To fair value or not to fair value: A broader perspective. Abacus, 44(2), 181-208. https://doi.org/10.1111/j.1467-6281.2008.00257.x

Salin, P. (2010). Revenir au capitalisme, pour éviter les crises. Jacob Odile.

Sangster, A. (2010). Using accounting history and Luca Pacioli to put relevance back into the teaching of double entry. Accounting, Business \& Financial History, 2o(1), 23-39.

Schildbach, T. (2015). Fair value accounting - Konzeptionelle Inkonsistenzen und Schlussfolgerungen für die Rechnungslegung. Vahlen.

Schmalenbach, E. (1959). Dynamic accounting (Murphy, G. W. y Most, K. S., trads.) Gee. (Original publicado en 1919).

Schmalenbach, E. (1933). Dynamische Bilanz (6. ${ }^{\mathrm{a}}$ ed.). Gloeckner.

Shafir, E. y Thaler, R. H. (2006). Invest now, drink later, spend never: On the mental accounting of delayed consumption. Journal of Economic Psychology, 27(5), 694712. https://doi.org/10.1016/j.joep.2006.05.008

Simon, H. A. (1981). The sciences of the artificial (2.. ed.). MIT Press.

Simon, H. A. (1990). Invariants of human behavior. Annual Review of Psyhology, 41, 119. https://doi.org/10.1146/annurev.ps.41.020190.000245

Smith, V. L. (2003). Constructivist and ecological rationality in economics. The American Economic Review, 93(3), 465-508.

Smith, V. L. (2005). Behavioral economics research and the foundations of economics. The Journal of Socio-Economics, 34, 135-150.

Smith, V. L. (2008). Rationality in economics. Constructivist and ecological forms. Cambridge University Press.

Solomons, D. (1961). Economic and accounting concepts of income. The Accounting Review, 36(3), 374-383.

Sombart, W. (1919). Der moderne Kapitalismus (Vol. 2,1). Duncker \& Humblot. 
Sunder, S. (2005). Minding our manners: Accounting as social norms. The British Accounting Review, 37, 367-387. https://doi.org/10.1016/j.bar.2005.08.007

Sunder, S. (2010). Adverse effects of uniform, written reporting standards on accounting practice, education, and research. Journal of Accounting and Public Policy, 29(2), 99-114. https://doi.org/10.1016/j.jaccpubpol.2009.10.011

Sunder, S. (2013). The problem of improving financial reporting. Izmir Review of Social Sciences, 1(1), 1-6. http://dx.doi.org/10.2139/ssrn.2286821

Thaler, R. H. (1980). Toward a positive theory of consumer choice. Journal of Economic Behavior and Organization, 1(1), 39-60.

Thaler, R. H. (1999). Mental accounting matters. Journal of Behavioral Decision Making, 12(3), 183-206. https://doi.org/10.1002/(SICI)1099-0771(199909)12:3<183::AID$\underline{\mathrm{BDM}} 318>3.0 . \mathrm{CO} ; 2-\mathrm{F}$

Walker, R. G. (1992). The SEC's ban on upward asset revaluations and the disclosure of current values. Abacus, 28(1), 3-35. https://doi.org/10.1111/j.14676281.1992.tbo0267.x

Watts, R. L. (2003). Conservatism in accounting part I: Explanations and implications. Accounting Horizons, 17(3), 207-221. http://dx.doi.org/10.2139/ssrn.414522

Watts, R. L. y Zimmerman, J. L. (1986). Positive accounting theory. Prentice-Hall.

Waymire, G. B. (2014). Neuroscience and ultimate causation in accounting research. The Accounting Review, 89(6), 2011-2019. https://doi.org/10.2308/accr-50881

Waymire, G. B. y Basu, S. (2008). Accounting is an evolved economic institution. Foundations and Trends in Accounting, 2(1-2), 1-173. http://dx.doi.org/10.1561/1400000011

Waymire, G. B. y Basu, S. (2011). Economic crisis and accounting evolution. Accounting and Business Research, 41(3), 207-232.

Williams, E. E. y Findlay III, M. C. (1980). Beyond neoclassical economic theory as a foundation for financial accounting. Abacus, 16(2), 133-141.

Yamashita, K. (1966). Accounting of allowance for lost cost - valuation at the lower of cost or market reconsidered. The Annals of the School of Business Administration, $10,1-8$. 
Yuan, M. y Liu, H. (2011). The economic consequences of fair value accounting. Accounting, Economics, and Law, 1(2), 1-44. https://doi.org/10.2202/2152$\underline{2820.1010}$

Zan, L. (1994). Toward a history of accounting histories. European Accounting Review, 3(2), 255-310.

Zeff, S. A. (2007). The SEC rules historical cost accounting: 1934 to the 1970s. Accounting and Business Research, 37(1), 49-62.

https://doi.org/10.1080/00014788.2007.9730085 